\title{
Clearance of man made mineral fibres from the lungs of sheep
}

\author{
A Dufresne, G Perrault, H Yamato, S Massé, R Bégin
}

McGill University, Department of Occupational Health, Faculty of Medicine, 3450 University Street, Suite 22, Montréal, Québec H3A 2A7,

Canada

A Dufresne

Institut de recherche en santé et sécurité du travail, Direction des opérations, 505 Ouest, de Maisonneuve, Montréal, Québec H3A 3C3, Canada G Perrault

Department of Environmental Health Engineering, University of Occupational and Environmental Health, 1-1 Iseigaoka

Yahatanishi

Kitakyushu, 807 Japan H Yamato

Centre Hospitalier de l'Université de

Sherbrooke,

Sherbrooke, Québec

J1H 5N4, Canada

S Massé

R Bégin

Correspondence to: Dr A Dufresne, McGill University, Department of Epidemiology, Biostatistics and Occupational Health, Faculty of Medicine, 3450 University Street, suite 22, Montréal, Québec H3A 2A7, Canada.

Accepted 10 June 1999

\begin{abstract}
Objectives-To compare the clearance rate, the related pathology, and the chemical and morphological changes of three man made mineral fibres (MMMFs) in the sheep model of pneumoconiosis.

Methods-Fibrous particles were extracted from lung parenchyma and analysed by transmission electron microscopy (TEM) and energy dispersive spectroscopy (EDS).

Results-The concentration of MMMF11, MMMF21, refractory ceramic fibre (RCF$1)$, and crocidolite asbestos fibres decreased with time according to a slow and a fast kinetic component. There was a statistical difference in the four regression lines as a function of time and the type of fibres $(p<0.001)$. The diameter of MMMFs decreased during the course of the time, whereas the crocidolite fibres did not seem to show any change. There was a statistical difference in the four regression lines as a function of time $(p=0.037)$ and type of fibres $(p<0.001)$. Ferruginous bodies were counted in the 40 sheep for which the latency period was 2 years. No typical ferruginous bodies were found in the groups exposed to MMMFs. The geometric mean concentration of asbestos bodies in the group exposed to crocidolite was 2421 bodies/g lung tissue (95\% CI 385 to 15260).

Conclusions-The number of initially retained fibres decreased with time according to a slow and a fast kinetic component. MMMF11 and MMMF21 have similar clearance, faster than RCF-1 and crocidolite. The geometric mean diameter and length of MMMF decreased with time, but crocidolite did not. After 2 years in the sheep tracheal lobe, ferruginous bodies were not found in all three MMMF groups but were substantial in the crocidolite group. Clearance is thought to proceed through dissolution and macrophage translocation.

(Occup Environ Med 1999;56:684-690)
\end{abstract}

Keywords: man made mineral fibres; retention in lung

Most of the concern about the potential hazards of respirable fibres has its origin from the so called "fibre carcinogenesis theory" in which morphological variables as well as biopersistence confer toxicological properties to these fibres. ${ }^{12}$ Because man made mineral fibres (MMMFs) contain fibres that can be inhaled and deposited within the lungs, con- cerns have been stressed about their potential health hazards. As a mechanism of action for any fibre has yet to be specifically identified, it is often anticipated that differences in toxicity of fibres of similar geometry are primarily related to biopersistence, which includes fibre solubility. Animal experiments are an interesting option to test the toxicity and evaluate the biopersistence of MMMFs in the lung. ${ }^{34}$

The first toxicological assays of MMMFs gave different results depending upon the way the fibres were delivered into the lungs (inhalation or intratracheal or intraperitoneal instillation). Inhalation assays did not show a significant excess of lung cancer or mesothelioma ${ }^{5-11}$ whereas the instillation of fibres in rat pleura or peritoneum produced a significant excess of mesothelioma. ${ }^{12-17} \mathrm{Re}-$ cently, significant adverse health effects were produced by chronic inhalation, with large doses of a refined fraction of refractory ceramic fibres (RCFs) ${ }^{18-23}$ whereas vitreous fibres did not show any significant increase of lung tumour or fibrosis.

Studies which have investigated the solubility and the physical durability of fibres showed that MMMFs had half lives shorter in animal models than amphibole asbestos fibres. ${ }^{11-28}$ It was also found that the biopersistence of fibres is a complex phenomenon and that many questions remain without answers or need to be consolidated with animal models other than the rat or hamster. One of these questions relates to the phenomenon of transformation (change in the morphology and in the chemical composition) when the fibre is stored in human lungs. Indeed, a lung concentration study ${ }^{29}$ reported that the only markers of the exposure were the siliceous fibres found at low concentration in the lungs of the exposed workers. The authors hypothesised that the absence of the original fibres in the lung was caused by the fact that these fibres were not respirable or that the fibres did not survive in the lung environment.

To test these hypotheses, we designed a long term animal study with the sheep model of pneumoconiosis. The main advantage in using sheep is that their lungs are about $60 \%-70 \%$ the size of the human lungs; clinical evaluation can be performed exactly as it is performed for humans and diseases related to fibrotic dusts such as asbestos, ${ }^{30}$ quartz, ${ }^{31}$ and silicon carbide fibres, ${ }^{32}$ which are found in humans can be reproduced in the sheep lungs. Overall, physiological conditions of sheep lungs are likely to be closer to human lungs than are those of rodent lungs. 

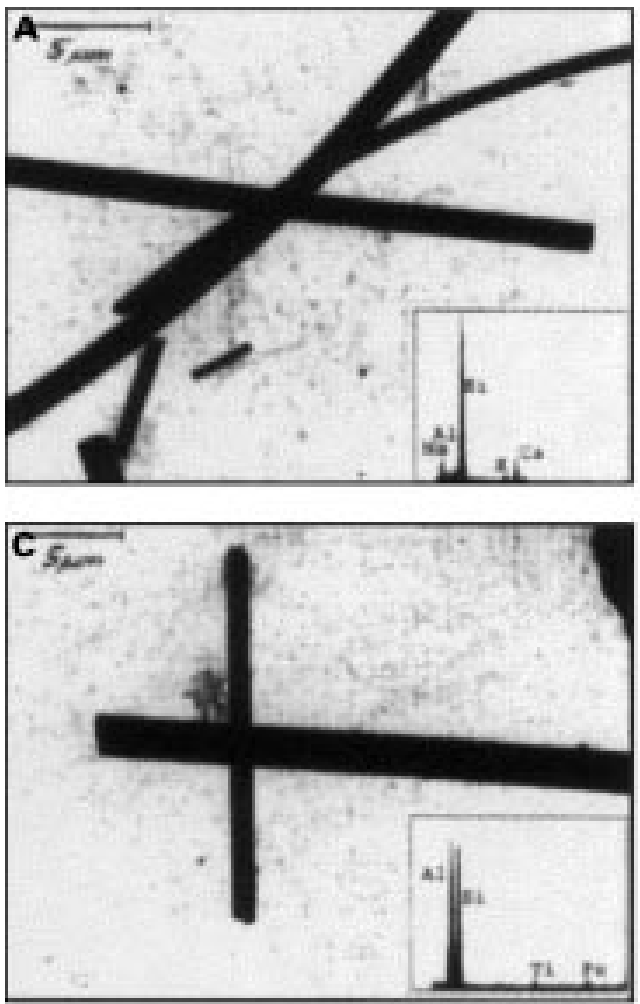

Figure 1 Transmission electron microscope view with energy dispersive spectra of $M M M F 11$ and $M M M F 21, R C F-1$, and crocidolite asbestos fibres.

The first objective of the present study was to compare the clearance rate of three reference samples of MMMF, a glasswool fibre (MMMF11), a rockwool fibre (MMMF21), and a ceramic fibre (RCF-1) with crocidolite asbestos fibre, as a comparison control. A single dose of each type of fibre was tested in the sheep model of pneumoconiosis. The second objective was to ascertain the pathology related to MMMFs in the sheep model for a dose that is known to produce grade 1 fibrosis (peribronchioalveolar fibrosing alveolitis) with crocidolite. The third objective was to test the hypothesis that the fibres did not survive in the lung environment by comparing the chemical and morphological nature of residual fibres.

\section{Material and methods}

ANIMALS

Two hundred and forty sheep weighing between 25 and $45 \mathrm{~kg}$ were used in this study. They were prepared and accustomed to the preliminary techniques as previously reported by Bégin et al (1985). ${ }^{33}$ All sheep were enrolled at the age of 1 year. Their health was verified by physical examination, serology test for brucellosis and Maedi visna infection, by a chest radiograph, pulmonary function tests, and a bronchoalveolar lavage. Abnormalities of one of these excluded the animal from the experimental protocol. Animals were housed in the animal care facility of Sherbrooke University and fed once a day hay and multigrain feeding and had access to water except on the day of examination. The research protocol was approved by the animal experimentation committee of Sherbrooke University.
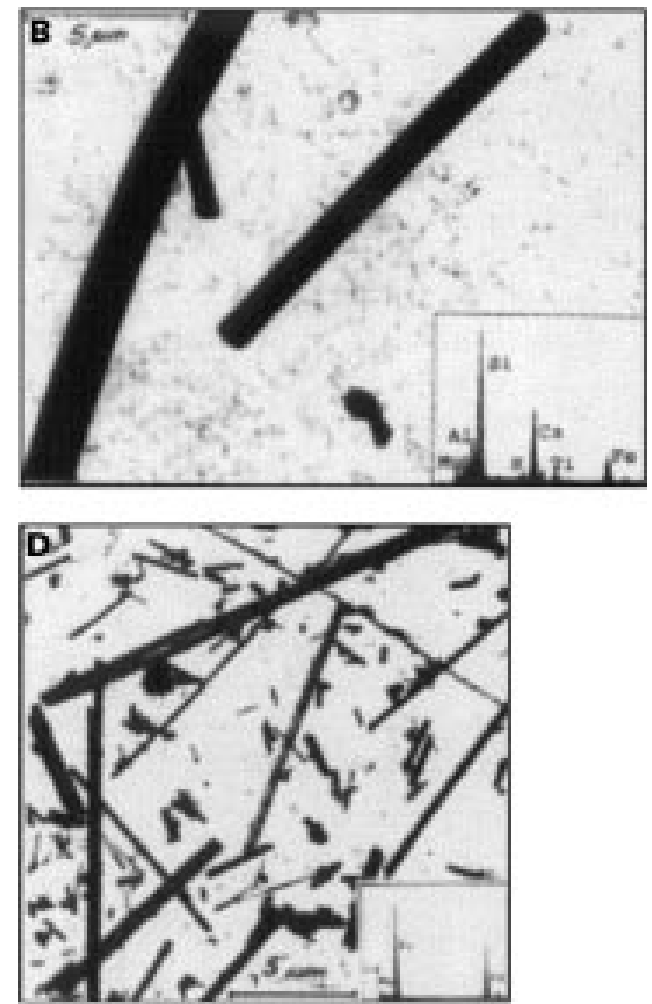

FIBRES AND EXPOSURE

The composition and the size of the MMMF samples have been already described elsewhere. ${ }^{34}$ They consist of MMMF11 (fibreglass), MMMF21 (rock wool), one ceramic fibre sample, RCF-1 (kaolin based), and crocidolite asbestos fibres (fig 1) as a comparison control.

The exposure was carried out in the sheep tracheal lobe through bronchoscopic catheterisation of the tracheal lobe bronchus and slow infusion of a suspension in the lobe. For each type of fibre, the suspension consisted of 100 $\mathrm{mg}$ fibres in $100 \mathrm{ml}$ saline.

\section{EXPERIMENTAL DESIGN}

Sheep, 10 from each group, were killed and the lungs were removed from the chest cavity at days $6,40,60,180,360$, and 730 . The dose and days from instillation were selected arbitrarily to reproduce the grade 1 fibrosis (peribronchoalveolar fibrosing alveolitis) with crocidolite and to allow the fibres enough time to dissolve. For each sheep, the tracheal lobe was identified and nine samples were obtained for histopathological examination. The remaining tissue was used for fibre analysis.

The lung samples were processed as routinely done for human lung tissue. Each sample was evaluated histologically for intensity and profusion of lesions to give an average qualitative evaluation of disease. ${ }^{33}$

ANALYSIS OF FIBRES AND FERRUGINOUS BODIES The number and size distribution of fibres in lung tissue were measured as follows. The analytical transmission electron microscopy 
Table 1 Histopathlogical evaluation

\begin{tabular}{|c|c|c|c|c|}
\hline Days & $M M M F 11$ & $M M M F 21$ & $R C F-1$ & Crocidolite \\
\hline 6 & $\begin{array}{l}\text { Alveolitis, no lesion, none or } \\
\text { few fibres }\end{array}$ & Alveolitis, no lesion, few fibres & Light aveolitis, few fibres & Peribronchiolar inflammatory lesions, few fibres \\
\hline 40 & $\begin{array}{l}\text { Alveolitis, no lesion, none or } \\
\text { few fibres }\end{array}$ & $\begin{array}{l}\text { Alveolitis, no lesion, notable } \\
\text { amount of fibres }\end{array}$ & $\begin{array}{l}\text { Alveolitis, notable amount of } \\
\text { fibres }\end{array}$ & Peribronchiolar inflammatory lesions, few fibres \\
\hline 60 & No lesion, none or few fibres & Alveolitis, no lesion, few fibres & Alveolitis, few fibres & Peribronchiolar inflammatory lesions, few fibres \\
\hline 180 & No lesion, none or few fibres & Alveolitis, no lesion, few fibres & Alveolitis, few fibres & $\begin{array}{l}\text { Peribronchiolar inflammatory lesions or without lesion, } \\
\text { few fibres }\end{array}$ \\
\hline 360 & No lesion, none or few fibres & $\begin{array}{l}\text { Alveolitis, no lesion, notable } \\
\text { amount of fibres }\end{array}$ & $\begin{array}{l}\text { Light alveolitis, no lesion, few } \\
\text { fibres }\end{array}$ & $\begin{array}{l}\text { Peribronchiolar lesions, beginning of fibrosis, notable } \\
\text { amount of fibres }\end{array}$ \\
\hline 720 & No lesion, none or few fibres & Alveolitis, no lesion, few fibres & No lesion, very few fibres & No significant lesion, interstitial pneumotitis, few fibres \\
\hline General & No lesion & Alveolitis & Light alveolitis & Inflammatory lesions \\
\hline
\end{tabular}

procedures have already been described..$^{35-37} \mathrm{In}$ summary, lung tissue was digested in sodium hypochlorite solution. The suspension was filtered under vacuum on a cellulose ester membrane filter (Millipore) of $25 \mathrm{~mm}$ diameter and $0.45 \mu \mathrm{m}$ porosity $(10 \mathrm{mg}$ for analytical transmission electron microscopic analysis) with a Millipore filtration system. The $25 \mathrm{~mm}$ diameter and $0.45 \mu \mathrm{m}$ porosity membrane filter was ashed in an oxygen plasma furnace (LFE model $500,15 \mathrm{ml} / \mathrm{min}$ of $\mathrm{O}_{2}, 150 \mathrm{~W}$ ) for 4 hours. The ashes were then recovered with distilled and deionised water. The suspension was filtered on a polycarbonate membrane filter (Nuclepore) of $25 \mathrm{~mm}$ diameter and $0.2 \mu \mathrm{m}$ porosity. Four microscope grids were prepared from each sample by a carbon replica technique. The grids were observed in the transmission mode under a JEOL $100 \mathrm{CX}$ electron microscope equipped with an $x$ ray energy dispersive spectrometer (EDS, PGT system IV) with an accelerating voltage of $80 \mathrm{kV}$ and a magnification $\times 10000$.

From the four grids, 60 openings (or less if 60 fibres were counted) with an area of 6400 $\mu \mathrm{m}^{2}$ were randomly observed for fibrous particles. Each visible fibre $>1 \mathrm{~mm}$ on the screen (1 $\mathrm{mm}=0.09 \mu \mathrm{m})$ and having length:diameter
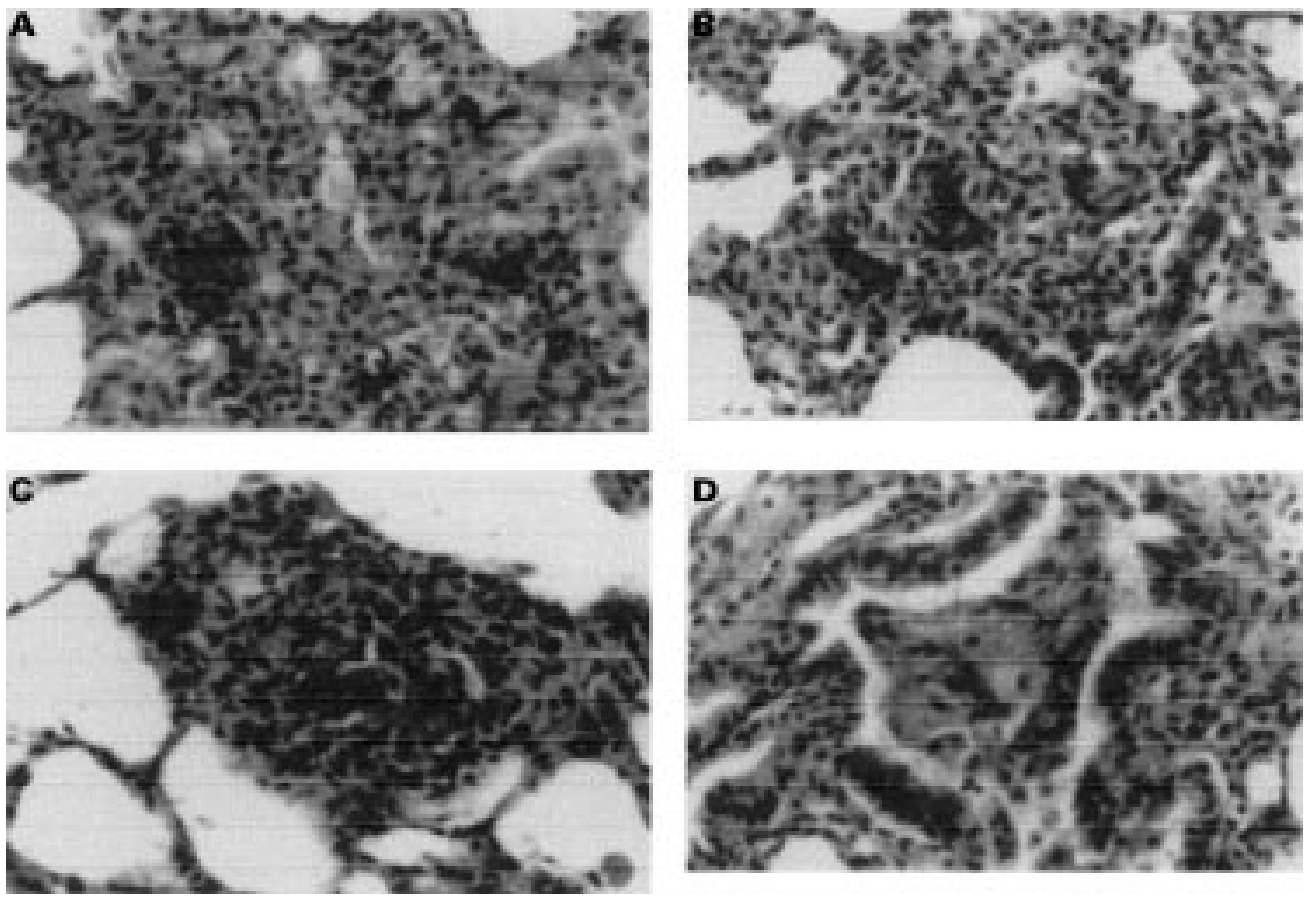

aspect ratio $\geqslant 3: 1$ was identified. Fibre types were recognised from morphological features and the EDS spectra shown in figure 1. All other fibres were classified as residual fibres. The length and diameter of all fibres were measured to the nearest $0.045 \mu \mathrm{m}(1 / 2 \mathrm{~mm}$ on the screen) with two concentric circles $(10 \mathrm{~mm}$ and $50 \mathrm{~mm}$ diameter) drawn on the fluorescent screen.

Lung digest filters $(25 \mathrm{mg}$ ) were used for optical microscope analysis of ferruginous bodies and were placed on $75 \times 38 \mathrm{~mm}$ microscopic glass slides and cleared with $85 \mathrm{ml}$ of a mixture of $35 \mathrm{ml}$ dimethylformamide, 20 $\mathrm{ml}$ glacial acetic acid, and $44 \mathrm{ml}$ water (DMF solution) in an oven at a temperature of $65^{\circ} \mathrm{C}$ for about 10 minutes. The cleared filters on glass slides were then mounted with microscopical cover glass with Eukitt mounting reagent.

STATISTICAL ANALYSIS

The statistical analyses were performed with Minitab statistical software (version 11). Lung retention data were log transformed to stabilise the variance and to obtain a more symmetric distribution. The fibres that could not be detected were assigned a value of half the limit

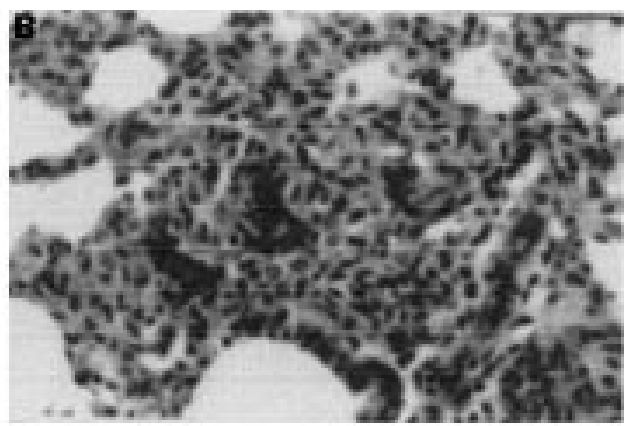

Figure 2 Histopathology (originally $\times 400$ ) of lung tissues from the tracheal lobe of sheep 6 days after intratracheal instillation. $A, B, C, D$ are respectively from $M M M F 11, M M M F 21, R C F-1$, and crocidolite fibres. 

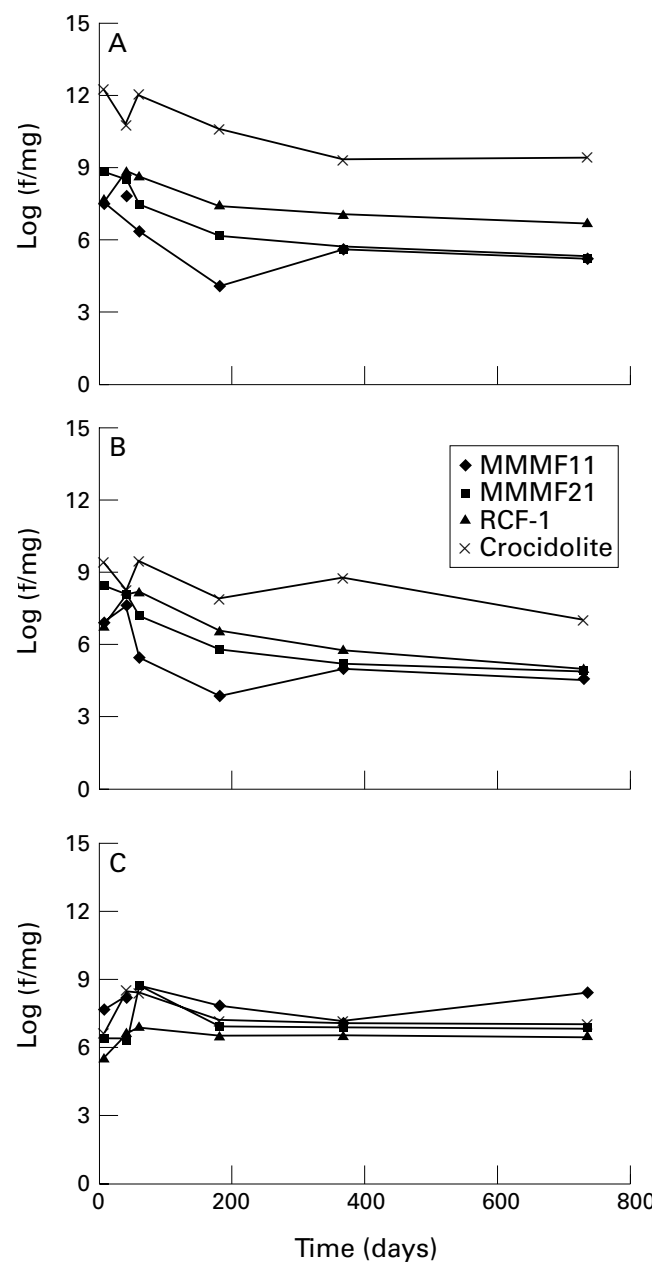

Figure 3 (A) Lung clearance of tested fibres for all lengths. (B) Lung clearance of tested fibres $>5 \mu \mathrm{m}$. (C) Concentration of residual fibres that did not show the same energy dispersive spectrum as the tested fibres.

of detection of the analytical method (and $\log _{\mathrm{e}}$ transformed). The limit of detection was 35 fibres $/ \mathrm{mg}$ for fibres, and 20 bodies $/ \mathrm{g}$ for ferruginous bodies. Geometric mean (GM) concentration of each fibre type was calculated from the $\log _{\mathrm{e}}$ concentration. For data analysis of particle size, the diameter and length of each fibre of each fibre type were $\log _{\mathrm{e}}$ transformed. The GM diameter and GM length of fibre type were computed for each sheep. The GM of each fibre type for each group was then calculated from these GMs of each sheep.

One way analysis of variance (ANOVA) of the log transformed concentrations was used to compare particle concentrations at days 6,40 , $60,180,365$, and 730 . The regression lines of concentrations on days were fitted by least squares. Half lives were estimated from the regression lines. Finally, possible differences in slopes according to exposure were investigated with analysis of covariance (ANCOVA).

\section{Results}

PATHOLOGY

Table 1 shows the lung pathology for each type of fibre over the time. In general, MMMF11 did not induce any lesion, MMMF21 resulted in alveolitis, RCF-1 slight alveolitis, and croci-
Table 2 Half life ( $\left.T_{1 / 2}\right)$ of fibres (all lengths) in the sheep lobe

\begin{tabular}{lll}
\hline Types of fibre & $T_{1 / 2}$ fast (days) & $T_{1 / 2}$ slow (days) \\
\hline MMF11 & $33-42^{\star}$ & 462 \\
MMF21 & 45 & 433 \\
RCF-1 & $67-156^{\star}$ & 537 \\
Crocidolite & $69-90^{\star}$ & 401 \\
\hline
\end{tabular}

${ }^{\star}$ With and without deviant points.

Table 3 Half life $\left(T_{1 / 3}\right)$ of fibres $\geqslant 5 \mu \mathrm{m}$ in the sheep lobe

\begin{tabular}{lll}
\hline Types of fibre & $T^{1 / 2}$ fast (days) & $T^{1 / 2}$ slow (days) \\
\hline MMF11 & $31-35^{\star}$ & 572 \\
MMF21 & 45 & 517 \\
RCF-1 & $61-157^{\star}$ & 254 \\
Crocidolite & $93-101^{\star}$ & 340
\end{tabular}

${ }^{\star}$ With and without deviant points.

dolite fibres some inflammatory peribronchiolar lesions. Diffuse interstitial lung disease was not found on any of the groups. Figure 2 shows a representative picture of the pathology for each type of fibre at day 6 .

CLEARANCE OF MINERAL FIBRES

The lung clearance of the tested fibres of all lengths and fibres $\geqslant 5 \mu \mathrm{m}$ are presented in figure $3 \mathrm{~A}$ and $\mathrm{B}$. These two parts of the figure were consistent with a fast and a slow kinetic component of the lung clearance of fibres. The half lives of each kinetic component for each type of fibre of all lengths and for fibres $\geqslant 5 \mu \mathrm{m}$ are shown in tables 2 and 3 respectively. There was a significant difference in the four regression lines presented in figure $3 \mathrm{~A}$ as a function of time (predictor 1 ) and the type of fibres (predictor 2) (ANCOVA, p<0.001).

ELEMENTAL COMPOSITION OF FIBRES

An appreciable amount of the residual fibres (fig $3 \mathrm{C}$ ) had a chemical composition showing only an $\mathrm{Si}$ peak or $\mathrm{Si}$ with an alkali or alkali earth element for the MMMF11 and MMMF21 fibres. The leaching process of the RCF-1 fibres seemed to start with the leaching of the element $\mathrm{Ti}$ and $\mathrm{Fe}$ although at 365 days or 730 days some fibres were still showing the presence of the two elements. The peak ratio of the $\mathrm{Al}: \mathrm{Si}$ did not seem to change much in the course of time. However, an exhaustive statistical analysis of the ratio of $\mathrm{Al}: \mathrm{Si}$ would be needed from many RCF-1s to verify this assertion. The ratio of the elements from the crocidolite fibres did not seem to change at all in the course of time.

MORPHOLOGY OF FIBRES OVER TIME

Figure $4 \mathrm{~A}-\mathrm{D}$ shows the change in the mean diameter and length for all tested and residual fibres during the course of time. Although the crocidolite fibres did not seem to show any change in the size of their diameter, the diameter of the MMMFs decreased during the course of time. The mean diameter showed a significant difference in the four regression lines as a function of the time (predictor 1, ANCOVA, $p=0.037$ ) and the type of fibres (predictor 2, ANCOVA, $\mathrm{p}<0.001$ ).

The MMMF21s were longer than any other type of fibre and the crocidolite fibres were always the shortest. There was a significant 

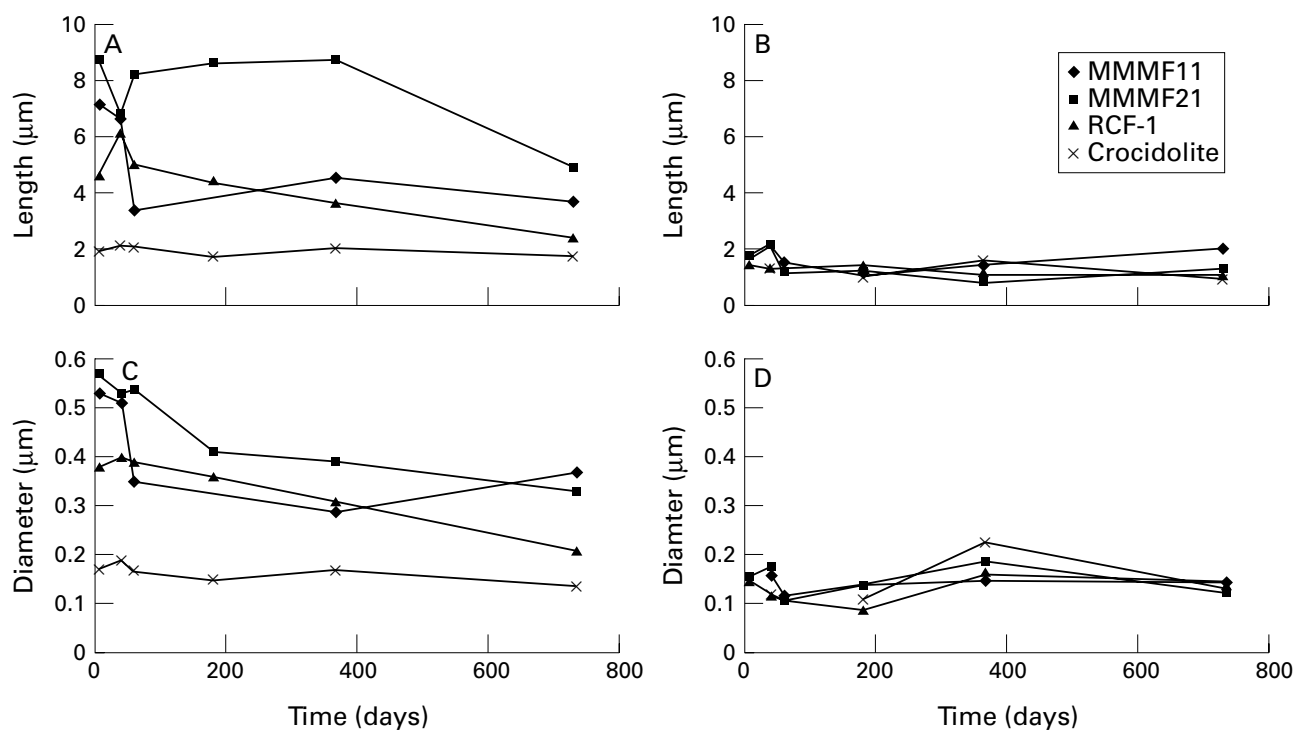

Figure 4 (A) Mean length of tested fibres. (B) Mean length of residual fibres. (C) Mean diameter of tested fibres. (D) Mean diameter of residual fibres.

difference for the length between each type of fibre but there was no significant difference in the length during the time course $(p>0.1)$. The residual fibres had smaller diameter and were shorter than the tested fibres at any point in time of the assay.

FERRUGINOUS BODIES

Ferruginous bodies were counted among the 40 sheep for which the latency period was 2 years. No typical ferruginous bodies were found in the groups exposed to MMMF11, MMMF21, and RCF-1. The geometric mean concentration of asbestos bodies in the group exposed to crocidolite fibres was 2421 bodies/g lung tissue (95\% CI of GM 385 to 15260 ).

\section{Discussion}

The sheep model has been useful in studying the pathophysiology of insterstitial lung disease and has contributed to the study of pulmonary clearance of asbestos, ${ }^{30}$ free silica, ${ }^{31}$ silicon carbide particles, and silicon carbide whiskers, ${ }^{32}$ despite its limitations of heterogeneous pulmonary distribution from intratracheal instillation. ${ }^{38}$

\section{PATHOLOGY}

The disease process induced by exposure to fibres resulted in an interstitial reactive inflammatory alveolitis, which subsided substantially in all groups over time with peribronchiolar alveolitis persisting only in the crocidolite group after 2 years. Thus it suggests that the process of fibre clearance was not compromised by a major disease process. The clearance pattern of the sheep exposed to crocidolite was consistent with earlier experiments in the sheep model of pneumoconiosis. ${ }^{39}$

FIBRE CONCENTRATION

An attempt was made to estimate the concentration of instillated fibres per unit mass. It was estimated that there were 5000-10 000 per $\mu \mathrm{g}$ MMMFs and about $1-1.5$ million fibres/ $\mu \mathrm{g}$ of crocidolite asbestos fibres. This property was reflected in the fibre concentration in the lungs of the differently exposed groups. As shown in figure 3 A there were 10-100 times fewer MMMFs than crocidolite fibres in the lungs at each point in time. Moreover, at 730 days, the GM concentration of all fibres was around 390 fibres/mg for MMMFs whereas it was in the range of 12000 fibres $/ \mathrm{mg}$ for the crocidolite fibres. Overall, these data support the results of Hesterberg et $a l^{40}$ who made similar findings with the rat model with exposure of 5 days.

HALF LIFE OF EACH TYPE OF FIBRE

Bernstein $e t a l^{41}$ showed a biphasic clearance curve of soluble MMMFs after inhalation in rats. In sheep, a few points deviated from this "ideal" clearance curve in two exposed groups-for example, MMMF11 and RCF1 -that are shown in figure $3 \mathrm{~A}$ and $\mathrm{B}$. The MMMF21 curve showed a "perfect biphasic" clearance curve. To give a better estimate of the rate of clearance, the ranges of half lives (estimated in table 2 and 3) were computed including and excluding the deviant points from the ideal curves. The inclusion or exclusion of the seemingly deviant points did not affect the final results significantly.

Moreover, the clearance half lives of our study were comparable with other studies ${ }^{20} 41-45$ that used intratracheal instillation or inhalation of similar types of fibres, mainly in rats (table 4). However, to be able to compare our results, it was necessary to use the same calculation methods for the regression curves that were used in each study. The half lives $\left(T_{1 / 2}\right)$ from a simple regression curve fitted through all the data under consideration do not differentiate between the different fibres except for two studies that have shown high values for crocidolite $^{42}{ }^{43}$ which are not in agreement with the sheep results. The weighted double regression half lives (W-T $\mathrm{T}_{1 / 2}$ ) as proposed by Bernsein $e t a l^{41}$ show a faster clearance of the 
Table 4 Half life ( $T_{1 / 2}$, days) of man made mineral fibres (MMMFs) in different animal models

\begin{tabular}{|c|c|c|c|c|c|c|c|c|}
\hline \multirow[b]{3}{*}{ Sample } & \multicolumn{4}{|c|}{ The present study } & \multicolumn{4}{|c|}{ Other studies (rats) } \\
\hline & \multicolumn{2}{|l|}{$T_{1 / 2} *$} & \multicolumn{2}{|l|}{$W-T_{t / 2} \star * *$} & \multicolumn{2}{|l|}{ Inhalation } & \multicolumn{2}{|c|}{ Intratracheal instillation } \\
\hline & All lengths & $f>5 \mu m$ & All lengths & $f>5 \mu m$ & All lengths & $f>5 \mu m\left(W-T_{T / 2}\right) \dagger$ & All lengths & $f>5 \mu m$ \\
\hline MMMF11 & 247 & 203 & 31 & 31 & $182^{42}, 249^{43}$ & $28^{41}$ & $199^{44}, 237^{42}$ & $272^{42}$ \\
\hline MMMF21 & 154 & 141 & 75 & 46 & $203^{43}$ & $54^{41}$ & $291^{44}, 258^{42}$ & $283^{42}$ \\
\hline RCF-1 & 280 & 192 & 280 & 154 & $\begin{array}{l}141^{43}, 177^{45} \\
316^{45}, 200^{20} \\
\text { (hamsters) }\end{array}$ & & $343^{44}, 190^{42}$ & $304^{42}$ \\
\hline Crocidolite & 231 & 301 & 175 & 105 & $301^{42}$ & & $185^{42}, 695^{43}$ & $976^{42}$ \\
\hline
\end{tabular}

*Simple regression.

+Weighted for a double regression, as reported by Bernstein et al. ${ }^{41}$

MMMF11 and the MMMF21 than the RCF-1 and the crocidolite.

CHANGE IN THE MORPHOLOGY OF FIBRES OVER TIME

The diameters and the lengths of the tested MMMFs were significantly different from the initial stock fibres which were reported respectively at about $1 \mu \mathrm{m}$ and $10 \mu \mathrm{m} .{ }^{46}$ It should be mentioned that a notable decrease in length seemed to happen between days 365 and days 730 for MMMF21 whereas the decrease seemed to be earlier for the MMMF11 and the RCF-1. Hesterberg et $a l^{40}$ also reported that MMMF21 exhibited the least chemical change among the MMMFs that they have tested. All these findings broadly agreed with a faster clearance of fibres $>20 \mu \mathrm{m}$ long as suggested now by many researchers. ${ }^{40} 447^{49}$ This reduction in the mean length of MMMFs in the lung has been attributed to extracellular dissolution or breakage to shorter fibres followed by macrophage clearance or a combination of these mechanisms. ${ }^{4041}$

Many experimental studies ${ }^{14} 4445485051$ have shown that the MMMFs have a tendency toward chemical and morphological changes as we have actually shown with the sheep model.

FERRUGINOUS BODIES

In the present study, ferruginous bodies coating fibres were not seen in all three groups of sheep that were instilled with MMMFs. However, notable amounts of ferruginous bodies were found in the group of sheep exposed to crocidolite. By contrast with the present study, Holmes et $a \bar{l}^{2}$ found that glass fibres instilled into hamsters were partially coated after 1 month (fibres 60 and $100 \mu \mathrm{m}$ long) or after 2 months (fibres 10 and $30 \mu \mathrm{m}$ long). Also, they reported that there were variations in the frequency of coated fibres in different animals killed at the same time but that coating tended to increase up to 5 months and then to decline. Morgan $^{53}$ showed that the time of appearance of coated glass fibres was similar to that found with anthophyllite asbestos fibres. The proportion of glass fibres that were coated seemed to increase over 3-4 months and then to decline. The time of onset of the formation of ferruginous bodies decreased with increasing fibre length and fibres $<10 \mu \mathrm{m}$ in length did not become coated.

Davis et $a l^{12}$ also found ferruginous bodies in their rats exposed to ceramic fibres. On the other hand, in their rats exposed to fibreglass or
RCF, Smith et al did not see ferruginous bodies coating fibres in any of the section of the lungs but they found some ferruginous bodies in one Syrian hamster exposed to RCF.

Synthesis of ferruginous bodies from refractory or vitreous fibres seems to be dependent of the animal model. Also, if the finding made with the sheep tracheal lobe can be extrapolated to human lungs, it is unlikely that ferruginous bodies from MMMFs could be used as markers of the exposure to vitreous fibres.

RESIDUAL FIBRES

The residual fibres were thinner and shorter than the tested fibres and have never reached the concentration of the tested fibres. The MMMF11 and MMMF21 samples showed losses of both alkali and alkaline earth oxides over the course of time. This loss seems to be more apparent at 40 days as appreciable amounts of siliceous fibres were then found among the residual fibres. For the purpose of a comparison, Hesterberg et $a l^{40}$ reported that MMMF10 and MMMF22 showed significant losses of both alkali and alkaline oxides as early as 1 hour after the end of the 5 day exposure period of their rats.

Finally, if the model of the tracheal lobes of sheep can be extrapolated to human lungs, the present study supports the hypothesis ${ }^{29}$ that the fibres do not seem to survive in the lung environment and this would explain why mainly residues of short siliceous fibres were found which in fact were similar to those extracted from the lungs of sheep.

\section{Conclusion}

The decrease over time of the number of initially retained MMMFs was reasonably well represented by a model consisting of a slow and a fast kinetic component (biphasic kinetic) which appeared clearly for MMMF21s. The MMMF11s and MMMF21s had similar clearance, faster than RCF-1 and crocidolite. Diameter and length of MMMFs decreased with time but this was not the case for crocidolite asbestos fibres. After 2 years in the sheep tracheal lobe, ferruginous bodies coating fibres were found only in the group exposed to crocidolite. Clearance is thought to proceed through dissolution and macrophage translocation and the data on residual fibres suggested that dissolution and translocation was occurring faster for the three MMMFs studied than for the crocidolite asbestos fibres. 
1 International Agency for Research on Cancer Monographs on the evaluation of carcinogenic risks to humans. Man-made mineral fibres and radon. Lyon: IARC, 1988;43.

2 De Vuyst P, Dumortier P, Swaen GMH, et al. Respiratory health effects of man-made vitreous (mineral) fibres. Eur Respir f 1995;8:2149-73.

3 McClellan RO, Miller FJ, Hesterberg TW, et al. Approaches to evaluating the toxicity and carcinogenicity of man-made fibres: summary of a workshop held 11-13 November
1991, Durham, North Carolina. Regul Toxicol Pharmacol 1992;16:321-64.

4 Bignon J, Brochard P, Gibbs G. Workshop MMMF: assessment of toxicity of man-made fibres. Paris, France, 3-4 February 1994. Ann Occup Hyg 1995;39:633-5.

5 Lee KP, Barras CE, Griffith FD, et al. Comparative pulmonary responses to inhaled organic fibres with asbestos and : Res 1981;24:167-91.

6 Goldstein B, Rendall REG, Webster IA. Comparison of the effects of exposure of baboons to crocidolite and fibrousglass dust. Environ Res 1983;32:344-59.

7 McConnell EE, Wagner JC, Skidmore JW, et al. A comparative study of the fibrogenic and carcinogenic effects of UICC Canadian chrysotile B asbestos and glass microfibre. (JM 100). In: Biological effects of man made mineral fibres. Vol 2. Copenhagen: World Health Organization, Regional Office for Europe, 1984;234-52.

8 Smith DM, Ortiz LW, Archuleta RF. Long-term exposure of Syrian hamsters and Osborne-Mendel rats to aerolized $0.45 \mu \mathrm{m}$ mean diameter fibrous glass. In: Biological effects
of man made mineral fibres. Vol 2. Copenhagen: World of man made mineral fibres. Vol 2. Copenhagen: World 253-72.

9 Wagner JC, Berry GB, Hill RJ, et al. An experiment with MMM(V)F: effects of inhalation and intrapleural inocculated rats. In: Biological effects of man made mineral fibres. Vol 2. Copenhagen: World Health Organization, Regional Office for Europe, 1984;209-33.

10 Muhle H, Pott F, Bellman B, et al. Inhalation and injection experiments in rats to test the carcinognicity of $M M M F$. Ann Occup Hyg 1987;31:755-64.

11 Le Bouffant L, Daniel H, Henin JP, et al. Experimental study on long-term effects of inhaled MMMF on the lung of rats. Ann Occup Hyg 1987;31:765-90.

12 Davis JMG, Addison J, Bolton RE, et al. The pathogenic effects of fibrous ceramic aluminium silicate glass adminstrated to rats by inhalation or peritoneal injection. In: Biological effects of man made mineral fibres. Vol 2. Copenhagen World Health Organization, Regional Office for Europe, 1984;303-22

13 Monchaux G, Bignon J, Jaurand MC, et al. Mesotheliomas in rats following inoculation with acid-leached chrysotile asbestos and other mineral fibres. Carcinogenesis 1981;2: 755-64.

14 Stanton MF, Layard M, Tegeris A, et al. Carcinogenicity of fibrous glass: pleural response in the rat in relation to fibre dimension. $\mathcal{F}$ Natl Cancer Inst 1977;58:587-603.

15 Stanton MF, Layard M, Tegeris A, et al. Relation of particle dimension to carcinogenicity in amphibole asbestos and other fibrous minerals. I Natl Cancer Inst 1981;6:965-75.

16 Pott F, Ziem U, Reiffer FJ, et al. Carcinogenicity studies on fibres, metal compounds, and some other dusts in rats. Exp Pathol 1987;32:129-52.

17 Smith DM, Ortiz LW, Archuleta RF, et al. Long-term health effects in hamsters and rats exposed chronically to man-made mineral fibres. Ann Occup Hyg 1987;31:731-54.

18 Hesterberg TW, Miiller WC, McConnell EE, et al. Chronic inhalation toxicity of sized-separated glass fibres in Fischer inhalation toxicity of sized-separated glass fibres

19 Hesterberg TW, Miiller WC, Mast R, et al. Relationship between lung biopersistence and biological effects of manmade mineral fibres after chronic inhalation in rats. Environ Health Perspect 1994;102:133-7.

20 Mast RW, Hesterberg TW, Glass LR, et al. Chronic inhalation and biopersistence of refractory ceramic fibre in rat and hamsters. Environ Health Perspect 1994;102:207-9.

21 Brown RC, Hoskins JA, Glass LR. The in vivo biological activity of ceramic fibre. Ann Occup Hyg 1995;39:705-13.

22 Rossiter CE, Chase JR. Statistical analysis of results of carcinogenicity studies of synthetic vitreous fibres at research and consulting company, Geneva. Ann Occup Hyg 1995;39: 759-69.

23 McConnell EE, Mast RW, Hesterberg TW, et al. Chronic inhalation toxicity of a kaolin-based refractory ceramic fibre in syrian golden hamsters. Inhal Toxicol 1995;4:50332.

24 Scholze J, Conradt R. An in-vitro study of the chemical durability of siliceous fibres. Ann Occup Hyg 1987;31:68392.

25 Bellmann B, Konig H, Muhle J, et al. Chemical durability of asbestos and man-made mineral fibres in vivo. 7 Aerosol Sci 1986;1:3-25.

26 Klingholz R, Steinkoff B. The reaction of MMMF in physiological model fluid and in water. In: Biological effects of man-made mineral fibres. Vol 2. Copenhagen: World Health man-made mineral fibres. Vol 2. Copenhagen: World Heat
27 Förster $\mathrm{H}$. The behaviour of mineral fibres in physiological solutions. In: Biological effects of man-made mineral fibres. Vol 2. Copenhagen: World Health Organization, Regional Office for Europe, 1984:27-59.

28 Leineweber JP. Solubility of fibres in vitro and in vivo. In: Biological effects of man-made mineral fibres. Vol 2 . Copenhagen: World Health Organization, Regional Office for Europe, 1984:87-101.

29 McDonald JC, Case BW, Enterline PE, et al. Lung dust analysis in the assessment of past exposure of man-made mineral fibre workers. Ann Occup Hyg 1990;34:427-41.

30 Bégin R, Cantin A, Massé S, et al. Contributions of experimental asbestosis in sheep to the understanding of asbestosis. Ann N Y Acad Sci 1991;643:228-38.

31 Bégin R, Dufresne A, Cantin A, et al. Quartz exposure retention and early silicosis in sheep. Exp Lung Res 1989;15:409-28.

32 Bégin R, Dufresne A, Cantin A, et al. Carborundum pneumoconiosis: fibres in the mineral activate macrophages to produce fibroblast growth factors and sustain the chronic inflammatory disease. Chest 1989;95:842-9.

33 Bégin R, Massé S, Rola-Pleszcynski M, et al. Selective exposure and analysis of the sheep tracheal lobe as a model for toxicological studies of respirable particles. Environ Res 1985;36:389-404.

34 Dufresne A, Bégin R, Perrault G. Persistence of man-made mineral (MMMF) fibres in the sheep tracheal lobe. In: Advances in the prevention of respiratory diseases. Chiyotani K, Hosoda Y, Aizawa Y, eds. Proceedings on the 9th International Conference on Occupational Respiratory Diseases. Kyoto, Japan: 1998;676-80.

35 Dufresne A, Sébastien P, Massé S, et al. Pulmonary clearance of fibrous and angular $\mathrm{SiC}$ particulates in the sheep model of pneumoconiosis. Ann Occup Hyg 1992;36: 519-30.

36 Dufresne A, Bégin R, Churg A, et al. Mineral fibre content of lungs in mesothelioma cases seeking compensation in of lungs in mesothelioma cases seeking compensation in

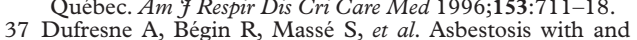
without lung cancer and mesothelioma: a study of lung concentration of asbestos fibres. Occup Environ Med 1996; 53:801-7.

38 Brain JD, Knudson DE, Sorokin SP, et al. Pulmonary distribution of particles given by intratracheal instillation or by aerosol inhalation. Environ Res 1976;11:13-33.

39 Sébastien P, Bégin R, Massé S. Mass, number and size of lung fibres in the pathogenesis of asbestosis in sheep. $\mathcal{F}$ Exp Path 1990;71:1-10.

40 Hesterberg TW, Miiller WC, Musselman RP, et al. Biopersistence of man-made mineral fibres and crocidolite asbestos in the rat lung following inhalation. Fundam Appl Toxicol 1996;29: 267-79.

41 Bernstein DM, Morscheidt C, Hans-Günther G, et al. Evaluation of soluble fibres using the inhalation biopersistance model, a nine-fibre comparison. Inhalation Toxicology 1996;8:345-85.

42 Muhle H, Bellmann B, Pott F. Comparative investigations of the biodurability of mineral fibres in the rat lung. Environ Health Perspect 1994;102:163-8.

43 Muhle H, Bellmann B. Biopersistance of man made vitreous fibres. Ann Occup Hyg 1995;5:655-60.

44 Bellmann B, Muhle H, Kamstrup O, et al. Investigation of durability of man-made mineral fibres in rat lung. Environ Health Perspect 1994;102:185-89.

45 Yamato H, Hori H, Tanaka I, et al. Retention and clearance of inhaled ceramic fibres in rat lungs and development of a dissolution model. Occup Environ Med 1994;51:275-80.

46 Luoto K, Holopainen M, Sarataho M, et al. Comparison of cytotoxicity of man-made mineral fibres. Ann Occup Hyg 1997;41:37-50

47 Bernstein DM, Morscheidt C, Tiesler H, et al. Evaluation of the biopersistence of commercial and experimental fibres following inahalation. Inhalation Toxicology 1995;7:103158 .

48 Morgan A. In vivo evaluation of chemical biopersistence of man-made mineral fibres. Environ Health Persepct 1994; man-made $127-31$

49 Musselman RP, Miiller WC, Eastes W, et al. Biopersistence of man-made mineral fibres and crocidolite fibres in rat lungs following short term exposures. Environ Health Perspect 1994;102(suppl 5):139-43.

50 Morgan A, Holmes A, Davidson W. Clearance of sized glass fibres from the rat lung and their solubility in vivo. Ann Occup Hyg 1982;25:317-22.

51 Bellman B, Muhle H, Pott G, et al. Persistence of man-made mineral fibres (MMMF) and asbestos in rat lungs. Ann Occup Hyg 1987;31:693-709.

52 Holmes A, Morgan A, Davidson W. Formation of pseudo-asbestos bodies on sized fibres in the hamster lung. In: Biological effects of man made mineral fibres. Vol 2. for Europe, 1984:303-22

53 Morgan A. Effect of length on the clearance of fibres from the lung and on body formation. In: Wagner JC, ed. Biological effects of mineral fibres. Vol 1. Lyon: International Agency for Research on Cancer, 1980;329-35. (IARC Sci Publ No 30.) 